\title{
Endoscopic Variceal Band Ligation: A Safe Way to Treat Oesophageal Varices
}

\author{
Ale Alexander Femi ${ }^{1}$, Achinge Godwin Ior ${ }^{2}$, Peter Solomon Danjuma ${ }^{1}$, Shitta Andrew Haruna ${ }^{1}$, \\ Misauno Michael Ayedima ${ }^{1}$ \\ ${ }^{1}$ Department of Surgery, Jos University Teaching Hospital, Jos, Nigeria \\ ${ }^{2}$ Department of Medicine, Benue State University Teaching Hospital, Makurdi, Nigeria
}

Email address:

falexale@yahoo.com (Ale A. F.)

${ }^{*}$ Corresponding author

\section{To cite this article:}

Ale Alexander Femi, Achinge Godwin Ior, Peter Solomon Danjuma, Shitta Andrew Haruna, Misauno Michael Ayedima. Endoscopic Variceal Band Ligation: A Safe Way to Treat Oesophageal Varices. Clinical Medicine Research. Vol. 5, No. 3, 2016, pp. 35-38.

doi: $10.11648 /$ j.cmr.20160503.14

Received: April 3, 2016; Accepted: April 20, 2016; Published: May 3, 2016

\begin{abstract}
Bleeding from oesophageal varices is the most dreaded complication of chronic liver disease and is associated with high mortality. Endoscopic variceal ligation is one of the more recent effective treatment modalities. This study was aimed at evaluating our experience with endoscopic variceal ligation with a view to stressing the safety associated with the procedure. A prospective study of consecutive patients presenting to the Jos University Teaching Hospital and FOMAS hospital endoscopic units was conducted over a 6 year period. A total of 199 sessions of endoscopic sessions were carried out on 83 patients with different grades of varices. There were 68 males and 15 females (M:F $=4.5: 1)$. The mean age of the study population was $48+/-$ 7.4 years with age range of 17 to 63 years. The number of sessions of banding required for variceal obliteration in this study varied from $43(51.8 \%)$ who had 3 sessions of banding, $30(36.1 \%)$ who had 2 sessions and $10(12.0 \%)$ that had a single session of variceal band ligation. All patients were placed on Propanolol tablets. There were no recorded episodes of procedure related bleeding, significant re-bleeding, post-procedure retrosternal pain, stricture or ulceration in this study, attesting to the safety of endoscopic variceal ligation.
\end{abstract}

Keywords: Oesophageal Varices, Varices, Endoscopic Variceal Ligation, Variceal

\section{Introduction}

Bleeding from oesophageal varices is the most dreaded complication of chronic liver disease and is associated with high mortality [1-2]. Early recognition and prompt treatment of this condition is therefore required for good patient outcome. The middle belt region of Nigeria where this study was carried out is endemic for Hepatitis $\mathrm{B}$ and $\mathrm{C}$ and consequently, has a high prevalence of oesophageal varices complicating the associated chronic liver disease.

Over the years, the treatment options for bleeding oesophageal varices has evolved from the different shunt procedures [3-4] performed by surgeons in these patients with poor anaesthetic risks, to drug management with vasopressors and somatostatin analogues [5-6], through mechanical tamponade with Sengstaken Blakemore and Minnesota tubes
[7-8] and finally the endoscopic treatment options [9-10]. With so many treatment options available for oesophageal varices, it is not easy getting to choose the most appropriate modality to use and this has generated considerable debate among care givers necessitating a treatment algorithm. It is generally agreed that the endoscopic treatment should be used first, both for primary and secondary prophylaxis, as well as during variceal bleeding and when torrential bleeding does not allow, use of balloon tamponade. Also when there is a significant re-bleed, Percutaneous Transjugular Intrahepatic Portosystemic Shunt should be used and the vasopressors are used as adjunct or as a stop gap measure in the emergency setting subject to availability. Before the advent of endoscopy in our practice, open surgical shunt procedures were the main stay of treatment and were associated with a high peri-operative morbidity and mortality. 
The endoscopic treatment options are becoming more widely available worldwide and are easy to perform with training and are safer for the patient. The two endoscopic treatment options available are: injection sclerotherapy using a variety of agents that are injected either intravariceally or perivariceally and endoscopic variceal band ligation. Of the two methods, rubber band ligation is far safer since it is associated with lower re-bleeding rates and fewer procedure related complications like oesophageal strictures, ulcers and required fewer sessions to achieve variceal obliteration [11-13]. This study is therefore aimed at evaluating our experience with endoscopic variceal ligation with a view to stressing the safety associated with this procedure.

\section{Patient and Methods}

This prospective hospital based study was carried out in the Jos University Teaching Hospital, a 526-bed hospital offering tertiary health care and FOMAS hospital, a minimal access surgery hospital that renders endoscopic services. These facilities receive patients from five neighboring states that have high endemicity of Hepatitis B and C. Patients from this study are drawn from the five states earlier mentioned in addition to Plateau state. Most of the patients present to the study locations because of the availability of expertise and equipment for therapeutic endoscopy services, which are largely unavailable in most of the other states from which the patients are drawn. The Jos University Teaching Hospital Ethics and Research Committee provided ethical clearance for this study and informed written consent was obtained from the patients. Consecutive patients presenting with upper gastrointestinal bleeding endoscopically confirmed to be variceal bleeding were recruited into the study, while those with grade 1 varices not suitable for band ligation, those with incomplete records, those withholding consent and children were excluded from this study. This study spanned a 6 year period (Jan 2010 to Dec 2015).

All patients had HIV and Hepatitis viral screens and those found positive were treated last on the list, while the scope was immersed in Umonium solution for 20 minutes for disinfection after each patient use.

Procedure: An initial upper gastrointestinal endoscopy was carried out with the patient lying on the left lateral position on a procedure couch and the endoscopist standing in front of the patient looking at the monitor, which is placed at the head end of the patient opposite the endoscopist. 10\% lignocaine was sprayed into the patient's mouth for anesthesia and a bite block was held in place between the upper and lower incisor teeth by an elastic band. A well lubricated forward- viewing GIF P30 Gastroscope was gently introduced under direct vision into the oesophagus. Gentle insufflation, suction and cleansing of the lens ensured good visibility of the varices and the Gastroscope was introduced far beyond the varices into the stomach and duodenum to exclude other causes of gastrointestinal bleeding. After ascertaining the cause of the bleeding to be varices, the endoscope is removed from the patient and a pre-loaded Saeed six shooter multi-band ligator was then mounted with the aid of a biopsy forcep unto the biopsy port of the endoscope. The endoscope with the mounted shooter was then lubricated and re-introduced in the manner described above to the level of the oesophagogastric junction, where the varices are more prominent. Each varix to be banded was briskly sucked into the cup of the shooter, as a band was quickly deployed to the base of the sucked up varix. After the deployment, the sunction is immediately stopped and the banded varix falls out of the cup. This is repeated to a maximum of three varices per session at slightly different levels and the endoscope is withdrawn out of the patient. The patient is then placed on liquid diet for 48 hours.

A re-endoscopy is performed 2 weeks after this to ascertain the need for further banding and to evaluate the previously banded varices. At this point, the varices would have sloughed off releasing the bands and getting obliterated in the process.

Data obtained from the patients included socio-demographic data, the grade of the varices, the number of sessions required for variceal obliteration and the complication encountered. This data was analyzed for basic statistics using Epi. info statistical software.

\section{Results}

A total of 199 sessions of endoscopic band ligation were carried out on 83 patients during the study period. There were 68 males and 15 females $(\mathrm{M}: \mathrm{F}=4.5: 1)$. The study population had a mean age of $48.7+/-7.4$ years. There was a wide variability in the age range of the study population which ranged from 17 to 63 years.

Fifty three patients (63.9\%) had grade 4 varices, 20 (24.1\%) had grade 3 varices and $10(12.0 \%)$ had grade 2 varices. Fifty patients $(60.2 \%)$ were on admission, while $33(39.8 \%)$ were treated on outpatient basis.

The number of sessions of banding required for variceal obliteration in this study varied from $43(51.8 \%)$ who had 3 sessions of banding, $30(36.1 \%)$ who had 2 sessions and 10 $(12.0 \%)$ that had a single session of variceal band ligation. All patients were placed on Propranolol tablets at a dose that achieved a $25 \%$ drop in the pulse rate.

There were no complications recorded in this study.

\section{Discussion}

The main finding in this study was that not a single patient had procedure related complications. This underscores the safety of this procedure and agrees with the work of several investigators who demonstrated a higher safety profile of rubber band ligation over sclerotherapy [14-16]. The high safety profile in this study may not be unconnected with the fact that prophylactic banding was done in most cases even without bleeding in predominantly in-patients. The maximum number of sessions of banding required to achieve variceal obliteration in this study was 3 over a 4-6 week period. Typically for in-patients, this took the form of a first banding session as soon as they were clinically stable, a second banding session before discharge and a third at follow-up. 
This finding is similar to results from several centers where rubber band ligation was compared with injection sclerotherapy and showed that far fewer sessions were required with banding to achieve variceal obliteration [17-19]. The fewer sessions of banding meant fewer risks of procedure related complications.

The male female ratio of 4.5:1 implies a male preponderance of oesoghageal varices seen in this study and can be explained by the male social habit of drinking alcohol typically seen in this environment, coupled with a higher prevalence of Hepatitis $\mathrm{B}$ and $\mathrm{C}$ infection among males [20-22]. These three are the main aetiologic agents associated with chronic liver disease and oesophageal varices.

The patient's ages spanned the 2 nd to 7 th decades with a mean age incidence at the 5 th decade. This suggests that no age is exempt from varices which are known to occur in pediatric age group. At the 5th decade in developing nations, people have generally peaked in their productivity and have reached management cadre and this is the age mostly affected by oesophageal varices with significant economic impact. The role of vertical transmission of Hepatitis and early development of liver cirrhosis with bleeding oesophageal varices could not be evaluated by this study, since the pediatric age group was excluded from this study.

Majority of the patients had graded 4 varices which connotes an advanced stage of the disease at presentation. This is typical of disease presentation in developing countries due to poverty, illiteracy and limited access to health care facilities.

More than half the patients were on admission at the time of presentation giving credence to the emergency nature of this disease and the attendant mortality and morbidity. Most of these admissions were for blood transfusion and treatment of the associated liver decompensation that comes with the background chronic liver disease.

Propanolol, a non-selective beta blocker plays a significant role in the reduction of portal pressure and all patients in this study were placed on it. Its low cost and availability makes it an important component of the therapy of oesophageal varices in this environment. It is useful in control of varices either alone or in combination with endoscopic treatment methods. Propanolol is so efficacious that some studies have compared it with endoscopic treatment methods and gone ahead to suggest that it should be used as first line treatment for primary prophylaxis and endoscopic band ligation be used when there are specific contraindications to use of beta blockers [23-25]. The main draw back with beta blockers has been its absolute or relative contraindication in some patients, associated side effects with increasing doses and the fact that not all patients respond to it. It's mechanism of action in reducing portal pressure is through both beta-1 and beta- 2 blockade, with the beta- 2 blockade being the more important effect. Beta-1 blockade decreases portal flow through a decrease in cardiac output and consequently hepatic arterial blood flow, while beta-2 blockade decreases portal blood flow through splanchnic vasoconstriction via unopposed alpha-adrenergic activity. Portal pressure is usually assessed by measurement of Hepatic venous pressure gradient (HVPG), an invasive procedure requiring technical expertise and a hemodynamic response to beta blocker therapy would be a $20 \%$ reduction in baseline HVPG, which is associated with significant protection against variceal bleeding [26-28]. Not all patients on beta-blocker therapy achieve a significant drop in portal pressure and since we do not have the capacity to routinely measure this drop in portal pressure, a reliable clinical goal is to titrate doses of propanolol to achieve a $25 \%$ reduction in pulse rate. While this is not always an indication of being a responder, it is easy, noninvasive and an acceptable method of monitoring adequate end points of beta-blocker therapy [29].

\section{Conclusion}

The fact that there were no recorded episodes of procedure related bleeding, significant re-bleeding, post-procedure retrosternal pain, stricture or ulceration in this study, attests to the safety of endoscopic variceal band ligation.

\section{Acknowledgment}

We acknowledge with gratitude the staff of the endoscopic unit of the Jos University Teaching Hospital and the staff and management of FOMAS hospital for their assistance in the conduct of this study.

\section{References}

[1] El Sayed G, Tarff S, O'Beirne J, Wright G. Endoscopy management algorithms: role of cyanoacrylate glue injection and self-expanding metal stents in acute variceal haemorrhage. Frontline Gastroenterol. 2015 Jul; 6(3): 208-16.

[2] Archampong TN, Tachi K, Agyei AA, Nkrumah KN. The Significance of Variceal Haemorrhage in Ghana: A Retrospective Review. Ghana Med J. 2015 Sep; 49(3): 142-6.

[3] Schettini AV, Pinheiro RS, Pescatore P, Lerut J. Modified Sugiura Operation for Idiopathic Portal Hypertension with Bleeding Oesophageal Varices. A Case Report. ActaChir Belg. 2015 May-Jun; 115(3): 237-40.

[4] Ruiz-Blard E, Baiges A, Turon F, Hernandez-Gea V, Garcia-Pagan JC. [Early Transjugular intrahepatic portosystemic shunt: When, how and in whom?]. Gastroenterol Hepatol. 2015 Nov 20.

[5] Rios Castellanos E, Seron P, Gisbert JP, Bonfill Cosp X. Endoscopic injection of cyanoacrylate glue versus other endoscopic procedures for acute bleeding gastric varices in people with portal hypertension. Cochrane Database Syst Rev. 2015; 5: CD010180.

[6] Drazna E. [Pharmacotherapy of portal hypertension]. VnitrLek. 1995 Mar; 41(3): 185-8.

[7] Avgerinos A, Armonis A. Balloon tamponade technique and efficacy in variceal haemorrhage. Scand J Gastroenterol Suppl. 1994; 207: 11-6.

[8] Seet E, Beevee S, Cheng A, Lim E. The Sengstaken-Blakemore tube: uses and abuses. Singapore Med J. 2008 Aug; 49(8): e195-7. 
[9] Sutedja DS, Kang JY. Endoscopic banding ligation treatment for bleeding oesophageal varices. Ann Acad Med Singapore. 1996 Sep; 25(5): 708-11.

[10] Serpa TH. [Endoscopic ligation of oesophageal varices]. Rev Gastroenterol Peru. 1996 Sep-Dec; 16(3): 244-8.

[11] Tait IS, Krige JE, Terblanche J. Endoscopic band ligation of oesophageal varices. Br J Surg. 1999 Apr; 86(4): 437-46.

[12] Bhuiyan MM, Rahman MM, Kibria MG, Hasan M. Comparative study of endoscopic band ligation and sclerotherapy for treatment of oesophageal varices in cirrhotic patients. Bangladesh Med Res Counc Bull. 2007 Apr; 33(1): $31-9$.

[13] Viazis N, Armonis A, Vlachogiannakos J, Rekoumis G, Stefanidis G, Papadimitriou N, et al. Effects of endoscopic variceal treatment on oesophageal function: a prospective, randomized study. Eur J Gastroenterol Hepatol. 2002 Mar; 14(3): 263-9.

[14] Laine L, el-Newihi HM, Migikovsky B, Sloane R, Garcia F. Endoscopy ligation compared with Sclerotherapy for treatment of bleeding esophageal varices. Ann Intern Med. 1993; 119(1): 1-7.

[15] Slosberg EA, Keefe EB. Sclerotherapy versus banding in the treatment of variceal bleeding. Clin Liver Dis. 1997; 1(1): 77-84.

[16] Dai C, Liu WX, Jiang M, Sun MJ. Endoscopic variceal ligation compared with endoscopic injection Sclerotherapy for treatment of esophageal variceal hemorrhage: a meta-analysis. World J Gastroenterol. 2015; 21(8): 2534-41.

[17] Svoboda P, Kantorova I, Ochmann J, Kozumplik L, Marsova J. A prospective randomized controlled trial of Sclerotherapy vs ligation in the prophylactic treatment of high-risk esophageal varices. Surg Endosc. 1999; 13(6): 580-4.

[18] Masci E, Stigliano R, Mariani A, Bertoni G, Baroncini D, Cennamo $\mathrm{V}$ et al. Prospective multicentre randomized trial comparing banding ligation with Sclerotherapy of oesophageal varices .Hepatogastroenterology. 1999; 46(27): 1769-73.

[19] Sarin SK, Govil A, Jain AK, Guptan RC, Issar SK, Jain M, Murthy NS. Prospective randomized trial of endoscopic sclerotherapy versus variceal band ligation for esophageal varices: influence on gastropathy, gastric varices and variceal recurrence. J Hepatol. 1997; 26(4): 826-32.
[20] Udeze AO, Okonko IO, Donbraye E, Sule WF, Fadeyi A, Uche IN. Seroprevalence of Hepatitis C virus Antibodies amongst blood donors in Ibadan, Southwestern, Nigeria. World Applied Sciences Journal. 2009; 7(8): 1023-1028.

[21] Halim NKD, Offor E, Ajayi OI. Epidemiological study of the seroprevalence of Hepatitis-B surface antigen $(\mathrm{HBsAg})$ and HIV-1 in blood donors. Nig J ClinPract 1992; 2: 42-5.

[22] Baba MM, Gashau W, Hassan AW. Detection of Hepatitis-B surface antigenaemia in patients mirth and without the manifestation of AIDS in Maiduguri, Nigeria. Nig Postgrad Med J 1998; 5: 125-8.

[23] Schepke M, Kleber G, Nurnberg D, Willert J, Koch L, Veltzke-Schlieker $\mathrm{W}$ et al. Ligation versus propanolol for the primary prophylaxis of variceal bleeding in cirrhosis. Hepatology 2004; 40: 65-72.

[24] Lay CS, Tsai YT, Lee FY, Lai YL, Yu CJ, Chen CB, Peng CY. Endoscopic variceal ligation versus propanololin prophylaxis of first variceal bleeding in patients with cirrhosis. J Gastroenterol Hepatol. 2006; 21: 413-419.

[25] Perez-Ayuso RM, Valderrama S, Espinoza M, Rollan A, Sanchez R, Otarola F et al. Endoscopic band ligation versus propanolol for the primary prophylaxis of variceal bleeding in cirrhotic patients with high risk esophageal varices. Ann Hepatol. 2010; 9(1): 15-22.

[26] Abraldes JG, Tarantino I, Turnes J, Garcia-Pagan JC, Rodes J, Bosch J. Hemodynamic response to pharmacological treatment of portal hypertension and long term prognosis of cirrhosis. Hepatology. 2003: 37(4): 902-8.

[27] Merkel C, Bolognesi M, Sacerdoti D, Bombonato G, Bellini B, Bighin R, Gatta A. The hemodynamic response to medical treatment of portal hypertension as a predictor of clinical effectiveness in the primary prophylaxis of variceal bleeding in cirrhosis. Hepatology. 2000; 32(5): 930-4.

[28] Grozmann RJ, Bosch J, Grace ND, Conn HO, Garcia-Tsao G, Navasa $M$ et al. Hemodynamic events in a prospective randomized trial of propanolol versus placebo in the prevention of a first variceal hemorrhage. Gastroenterology 1990; 99: 1401-1407.

[29] Tammy Tursi. Use of Beta-blocker therapy to prevent primary bleeding of oesophageal varices. J Am Acad Nurse Pract. 2010; 22(12): 640-647. 